\title{
BLUEBIRD RESCUE
}

\author{
RONALD A. BITTNER, Box 97, Abernethy, Saskatchewan. SOA OAO
}

I received a phone call in the afternoon of 25 June 1992 from an employee of a local auction firm. He had a problem involving bluebirds, and wondered if I could help. A farm implement had been transported a distance of about $20 \mathrm{mi}$. to the auction yard. It had arrived two days previously and was to be sold about two days hence. The machine was placed in a large shed overnight and during this time someone heard birds chirping. An investigation led to the discovery of a nest of young bluebirds in the machine.

I was told on the phone that these birds could not have eaten for two days, and there was no sign of adult birds going to the nest when the implement was parked outdoors. It was clear that these birds were doomed without quick human intervention, so I agreed to try to help. I drove the six mi. out to the auction yard equipped with an ice cream pail and some rags for padding and cover.

I was met by the employee who had phoned and he led me to the machine with the nest. I think it was a baler, although I am not certain because my attention was focused on the birds. The nest was in a horizontal pipe which extended from the machine to the tractor hitch. It was about two feet from the ground. The entrance hole was in the bottom of the pipe and was large enough to al- low us to reach into the pipe.

My friend reached in and brought out a fine young bluebird and placed it in the pail. It was fully feathered, and I estimated its age as about five days short of fledging. As the nest was at the end of his reach he had some difficulty retrieving the next three. Then I tested my reaching ability and brought out the last one. I covered the pail with a cloth and headed back to the car with the five young birds. On the way back to town there was much loud chirping. The pail seemed to amplify the sound and give it a three-dimensional quality such that the chirps seemed to come from various points in the car. I had difficulty believing that the birds were still in the pail, but my fears turned out to be groundless.

My plan was to place these young birds in one or more of my nestboxes which contained nestlings of about the same age. However, it was already late afternoon. Since the birds had not eaten for two days I thought it would be better to feed them and then place them in the boxes the next morning. The food menu that I offered contained only one item, mashed hard-boiled egg moistened slightly with water or vegetable oil.

I held the bird in one hand, holding its bill open with thumb and fore- 
finger. With the other hand I poked a small wad of food far back into its mouth so that it would swallow. If the food was not placed far back the bird would shake its head and the food would end up on my face or elsewhere. I fed each bird once per hour for three hours. It was a messy job and obviously should be left to the parent birds if possible.

The next morning one of the birds was dead. In spite of this unfortunate setback, it was now time to find a new home for the remaining four. At the time there was a very limited choice of nestboxes with young birds of similar age. Most of my early broods had already fledged. I chose a box which had only one nestling. Initially there were five eggs in this box but some were broken or pecked by House Wrens leaving only one to hatch. The positive factor about using this box was that the parent would not be overworked feeding five nestlings. The negative point was that the original nestling was about seven days younger than the newcomers.

I expected some difficulty getting the four birds to accept their new home because they were so near to fledging age. I transferred them one at a time from the pail to the box. Before I had them all in the box, one had jumped out and dropped into the long grass under the box. I pounced on it and returned it to the box. By this time I had some doubt whether this bluebird rescue operation would be successful. Would the nestlings stay in the box? Would the parents accept these new mouths to feed thereby increasing their workload considerably? Would the one young nestling be adversely affected by this exercise? However, I felt that I could do no more for them. I closed the box and quickly walked away, letting nature take its course.

Two days later I went on one of my regular nestbox monitoring trips. I opened the crucial box not knowing what to expect. What a pleasant surprise to see four healthy and contented bluebirds. I closed the box quickly and moved on because it is unwise to disturb birds that are near fledging. I did not see the fifth, younger nestling during my quick inspection. I wondered if it was getting any food competing with four larger siblings.

My next monitoring trip was a week later, and resulted in another pleasant surprise. The four older birds had fledged successfully. The original nestling looked healthy and contented. It had obviously received enough to eat for the previous nine days during which it had gained, and then lost, four nest mates. But would the adults continue to feed this lonely nestling for several days after the others had fledged?

Another week passed before the next monitoring trip. This time the box was empty. The last youngster had fledged successfully. This was a happy ending to the rescue operation. My bluebird fledge total for 1992 was 66 regular and 4 adopted. 